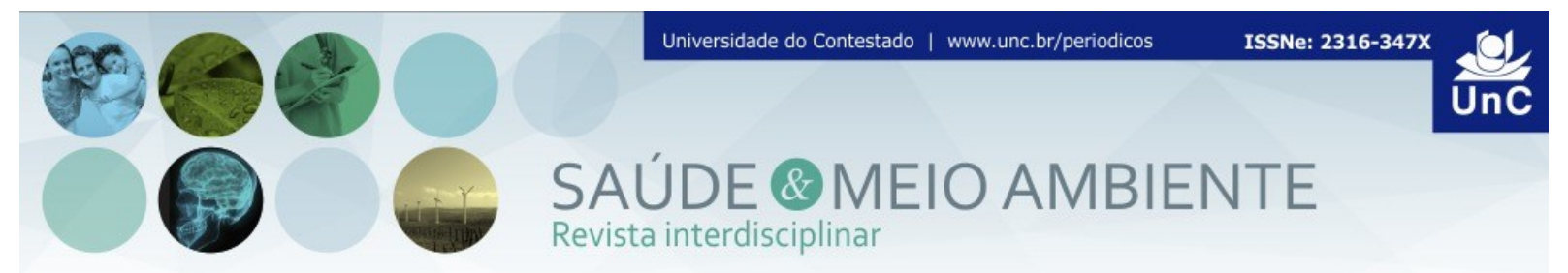

\title{
TOXICIDADE CELULAR DO HERBICIDA GLIFOSATO SOBRE OS OVÁRIOS DO PEIXE DANIO RERIO
}

\author{
Tainan Filipe da Silva ${ }^{1}$ \\ Kamilla Bleil do Carmo ${ }^{2}$ \\ Neide Armiliato ${ }^{3}$
}

\begin{abstract}
RESUMO
No oeste do estado de Santa Catarina, a agricultura é a atividade econômica predominante, visando à produção de milho, soja e produtos destinados à pecuária. Para manter tais produções, este setor utiliza intensamente insumos químicos, como fertilizantes e agrotóxicos, causando poluição nos ecossistemas. Dentre os resíduos químicos, os agrotóxicos são os mais tóxicos, constituídos por uma grande variedade de compostos, que afetam os organismos animais e vegetais. Este estudo objetivou avaliar a toxicidade do herbicida glifosato na concentração de $65 \mu \mathrm{g} / \mathrm{L}$ e o dobro desta concentração $120 \mu \mathrm{g} / \mathrm{L}$, nos ovários do peixe Danio rerio. Os peixes permaneceram expostos às concentrações do herbicida glifosato por 15 dias para o cálculo do Índice Gonadossomático (IGS) e massa corporal. Para o teste de micronúcleos os peixes ficaram expostos por 3 dias às diferentes concentrações de glifosato. Não houve diferença estatística significativa na massa corporal dos grupos experimentais avaliados. Houve diferença estatística significativa $(p<0,05)$ na massa dos ovários do grupo controle quando comparado com os grupos expostos a diferentes concentrações de glifosato. Em relação ao IGS houve diferença significativa entre as diferentes concentrações de glifosato e também em relação ao grupo controle. Porém a concentração de $120 \mu \mathrm{g} / \mathrm{L}$ apresentou maior diferença em relação à concentração de $65 \mu \mathrm{g} / \mathrm{L}(p<0,05)$. A frequência de micronúcleos e IGS dos peixes expostos ao glifosato, em ambas as concentrações, foram estatisticamente significativas em relação ao grupo controle. Portanto concluiu-se que o glifosato tem um potencial genotóxico em ambas as concentrações e pode causar danos a reprodução dos peixes.
\end{abstract}

Palavras-chave: Poluição. Micronúcleos. Genotóxico. Concentrações.

\footnotetext{
${ }^{1}$ Graduação de Bacharel em Ciências Biológicas. Universidade do Contestado. Santa Catarina. Brasil. E-mail: tainanfilipe@hotmail.com

${ }^{2}$ Graduação de Bacharel em Ciências Biológicas. Universidade do Contestado. Santa Catarina. Brasil. E-mail: kamillableil@hotmail.com

${ }^{3}$ Doutora em Biologia Celular e do Desenvolvimento (UFSC). Universidade do Contestado. Santa Catarina. Brasil. E-mail: armiliato@unc.br
} 


\title{
GLYPHOSATE CELL TOXICITY OF THE FISH OVARIANS Danio rerio
}

\begin{abstract}
The west of the state of Santa Catarina, agriculture is the predominant economic activity, aiming at the production of corn, soybeans and products destined to livestock. In order to maintain such production, this sector uses intensive chemical inputs, such as fertilizers and agrochemicals, causing pollution in ecosystems. Among chemical residues, pesticides are the most toxic, consisting of a wide variety of compounds, which affect animal and plant organisms. The objective of this study was to evaluate the toxicity of the glyphosate herbicide at $65 \mu \mathrm{g} / \mathrm{L}$ and twice the concentration of $120 \mu \mathrm{g} / \mathrm{L}$ in the ovaries of the Danio rerio fish. The fish were exposed to concentrations of the glyphosate herbicide for 15 days to calculate the Gonadosomatic Index (GSI) and body mass. For the micronucleus test the fish were exposed for 3 days at different concentrations of glyphosate. There was no significant statistical difference in the body mass of the experimental groups evaluated. There was a statistically significant difference $(p<0.05)$ in the ovarian mass of the control group when compared to the groups exposed to different concentrations of glyphosate. In relation to the GSI there was a significant difference between the different concentrations of glyphosate and also in relation to the control group. However, the concentration of $120 \mu \mathrm{g} / \mathrm{L}$ presented a greater difference in relation to the concentration of $65 \mu \mathrm{g} / \mathrm{L}(\mathrm{p}<0.05)$. The frequency of micronuclei and GSI of the fish exposed to glyphosate in both concentrations were statistically significant in relation to the control group. In conclusion, glyphosate has a genotoxic potential at both concentrations and may cause damage to fish reproduction.
\end{abstract}

Keywords: Pollution. Micronuclei. Genotoxic. Concentrations.

\section{INTRODUÇÃO}

No oeste do estado de Santa Catarina, a agricultura é a atividade econômica predominante, visando à produção de milho e soja, produtos destinados principalmente à pecuária e a criação de suínos e aves. A economia do município de Concórdia tem por base a agroindústria, predominando a suinocultura, avicultura, pecuária de leite, culturas agrícolas e indústria alimentícia (SANTA CATARINA. SECRETARIA DE ESTADO DO DESENVOLVIMENTO URBANO E MEIO AMBIENTE, 1997).

Para manter tais produções, este setor utiliza intensamente insumos químicos, como fertilizantes e agrotóxicos, causando grande poluição nos ecossistemas (PIGNATI et al., 2017).

Por esta razão, nas últimas décadas houve um aumento no uso de agrotóxicos na região, resultando em um comprometimento da fauna e da flora, que 
pode levar a alterações significativas na biologia das espécies. Sendo importante salientar que, em longo prazo, a contaminação dos ambientes aquáticos pode culminar na diminuição das populações (FONSECA, 2007).

Também é necessário considerar as concentrações não letais dos agrotóxicos, cujos efeitos silenciosos, podem afetar tanto a morfologia, fisiologia e bioquímica dos tecidos orgânicos, provocando impactos em vários níveis moleculares e sistêmicos (BEGUM, 2004).

Os agrotóxicos possuem a capacidade de atingir os corpos d'água, através do lençol freático por meio da lixiviação, da infiltração da água das chuvas, da irrigação ou da percolação no solo (SCHUMACHER; HOPPE, 1998; GRISOLIA, 2005).

Por isso, a necessidade de se detectar e avaliar o impacto do glifosato, especialmente em concentrações subletais, no monitoramento da qualidade ambiental, levou ao estudo de respostas biológicas em diversas espécies, como equinodermas, moluscos, crustáceos e peixes (GOLDFARB et al., 1998).

De um modo geral, as respostas moleculares e celulares apontam para os sinais iniciais de perturbação, de forma que tais avaliações vêm sendo comumente utilizadas em programas de biomonitoramento (CAJARAVILLE et al., 2000; NIGRO et al., 2006). Bem como, a avaliação celular dos efeitos subletais causados por um estressor contribui para a caracterização precoce de efeitos mais severos que podem manifestar doenças ou até mesmo a morte (MONSERRAT et al., 2003).

Portanto, o uso de peixes em estudos toxicológicos tem se mostrado muito apropriado, pois este grupo apresenta respostas biológicas bastante similares aos grandes vertebrados, reforçando o caráter conservativo dos processos moleculares e celulares na escala animal (AL-SABTI, 1986; METCALFE, 1989).

A espécie $D$. rerio, conhecida popularmente como paulistinha ou zebra fish tem sido utilizada em diversos estudos envolvendo exposição a agentes tóxicos, pois apresenta sensibilidade quando exposto a produtos químicos por ser capaz de absorver de forma rápida os compostos que são diretamente adicionados na água e acumulá-los em diferentes tecidos. Estudos dão suporte ao uso de $D$. rerio como modelo experimental na avaliação dos efeitos subletais de toxicidade do herbicida glifosato sobre os ovários, no que tange a biologia reprodutiva desse peixe (ANDRADE, 2004).

Desta forma, considerando que a contaminação dos ambientes aquáticos por agrotóxicos na região do município de Concórdia é uma realidade preocupante, e que os peixes são alvos diretos desta contaminação, torna-se imprescindível a realização de estudos direcionados a avaliação da toxicidade celular do glifosato no peixe da espécie Danio rerio.

Neste contexto, o presente estudo teve o objetivo de avaliar a toxicidade do herbicida glifosato na concentração de $65 \mu \mathrm{g} / \mathrm{L}$ e o dobro desta concentração 120 $\mu \mathrm{g} / \mathrm{L}$, nos ovários do peixe Danio rerio. 


\section{METODOLOGIA}

Para o estudo foram utilizadas 21 fêmeas adultas de $D$. rerio (Figura 1). A aclimatação das fêmeas foi realizada em aquários com capacidade de 40 litros, contendo água corrente declorada por um período de 7 dias. Os peixes foram alocados na proporção de $1 \mathrm{~g}$ de peixe por litro.

Os peixes permaneceram expostos às concentrações do herbicida glifosato por 15 dias para o cálculo do Índice Gonadossomático (IGS) e massa corporal. Para o teste de micronúcleos os peixes ficaram expostos por 3 dias às diferentes concentrações de glifosato

Durante o período de exposição à temperatura se manteve na média de $27,5^{\circ} \mathrm{C}$ (Desvio padrão de $\pm 0,3$ ), $\mathrm{pH} 7,6$ (Desvio padrão de \pm 1 ), e fotoperíodo natural, consideradas condições ideais para o bem estar e manutenção de $D$. rerio em aquário. Os parâmetros de qualidade da água, como pH e temperatura, foram monitorados semanalmente e os peixes foram alimentados diariamente com ração comercial para peixe.

Figura 1 - Peixe fêmea de Danio rerio.

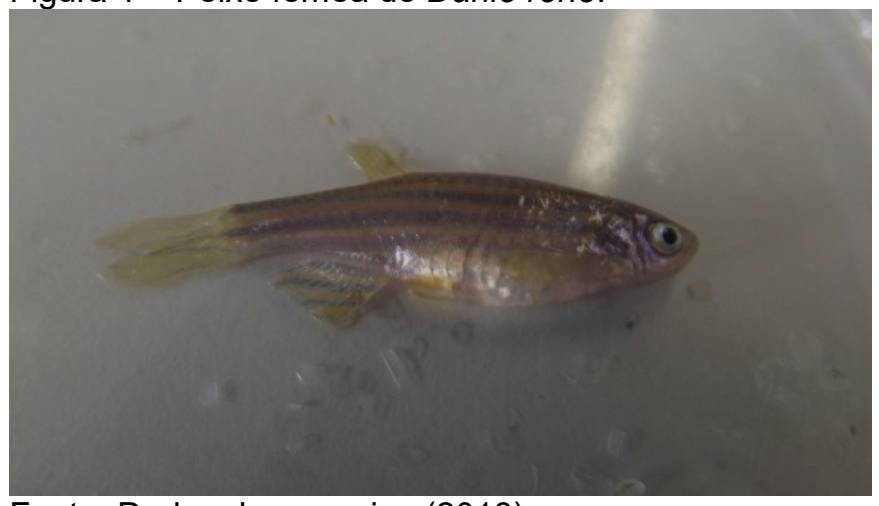

Fonte: Dados da pesquisa (2018).

Após a aclimatação, as fêmeas foram expostas em duas concentrações de glifosato diluído na água dos aquários, mantendo as mesmas condições de temperatura, $\mathrm{pH}$, fotoperíodo e alimentação, como no período de aclimatação.

Para contemplar os objetivos foram constituídos 3 grupos experimentais:

Grupo 1: Fêmeas $(n=7)$ expostas à concentração de $65 \mu \mathrm{g} / \mathrm{L}$ de glifosato diluído em água, concentração máxima permitida pelo CONAMA em rios brasileiros;

Grupo 2: Fêmeas $(n=7)$ expostas à concentração de $120 \mu \mathrm{g} / \mathrm{L}$ de glifosato diluído em água, concentração liberada nos Estados Unidos; 
Grupo 3: Fêmeas ( $n=7)$ não expostas ao glifosato.

Após o período de exposição por 15 dias, foi realizada a eutanásia dos peixes de cada grupo utilizando o hidrocloreto de benzocaína na concentração de $100 \mathrm{mg} / \mathrm{L}$ de água, conforme estudo realizado por Bittencourt et al. (2012).

Após anestesia, os peixes foram mantidos em água a $4^{\circ} \mathrm{C}$, por $5-10$ minutos. Em seguida foram obtidos os dados biométricos através das medidas peso $(\mathrm{g})$ e de comprimento total $(\mathrm{cm})$ dos peixes, esta última obtida pela distância entre a extremidade final da nadadeira caudal até a extremidade anterior da cabeça.

$\mathrm{Na}$ sequência, foi realizada a coleta de sangue, com auxílio de seringa previamente heparinizada em quantidade suficiente para dois esfregaços. Com base nestas amostragens, foi possível realizar um estudo de genotoxicidade através da frequência de micronúcleos nas hemácias dos peixes coletados, conforme metodologia de Cestari et al. (2004).

As lâminas foram processadas no laboratório de Análise Ambiental da UnCConcórdia, para secagem, fixação, coloração e análise. A secagem das lâminas foi realizada por no mínimo 12 horas, em temperatura ambiente e posição horizontal. As lâminas secas foram fixadas em álcool metílico por 10 minutos e secadas ao ar em temperatura ambiente por alguns minutos. Em seguida, foram coradas com Giemsa $5 \%$, por 25 minutos. Após a coloração, as lâminas foram lavadas em água destilada e secas ao ar. Foram visualizadas 6 lâminas de cada grupo contando um total de 2.000 eritrócitos por lâminas.

Os ovários foram dissecados, pesados (mg) e calculado o IGS. O IGS foi obtido através da relação entre a massa corporal (MC) e a massa da gônada (MG) de cada fêmea, utilizando-se a fórmula: IGS = $(M G / M C) \times 100$. O IGS foi utilizado como parâmetro para caracterizar as fases de maturação ovariana e inferir sobre os possíveis efeitos do glifosato nas fêmeas expostas.

\section{RESULTADOS E DISCUSSÃO}

\subsection{MASSA DAS GÔNADAS}

A massa das gônadas das fêmeas expostas às concentrações de glifosato variou de $0,013 \mathrm{mg}$ a $0,025 \mathrm{mg}$. As fêmeas do grupo controle apresentaram massa gonadal significativamente menor quando comparadas as fêmeas que foram expostas a diferentes concentrações de glifosato (One-Way ANOVA, $\mathrm{P}<0,05$ ) (Gráfico 1). 
Gráfico 1 - Massa das gônadas das fêmeas $D$. rerio expostas aos tratamentos ( \pm Desvio Padrão). Letras diferentes entre os tratamentos indicam diferenças estatísticas (Teste One-Way Anova, $p<0,05)$.

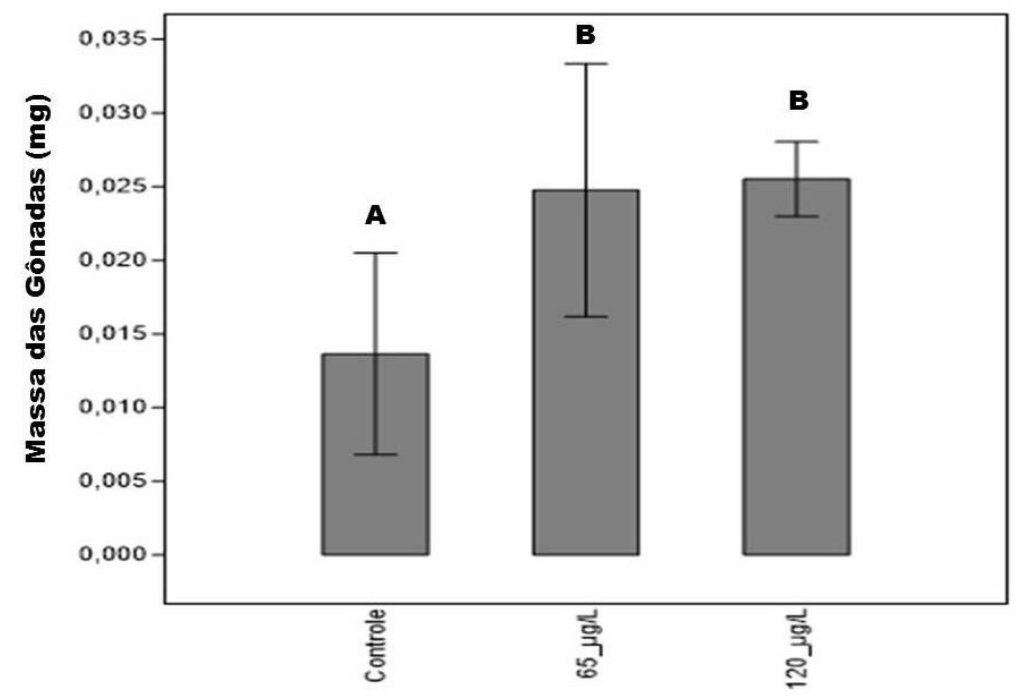

Fonte: Dados da pesquisa (2018).

Os dados apresentados mostram que houve diferença significativa entre a massa dos ovários dos peixes expostos a diferentes concentrações de glifosato quando comparado com o grupo controle (One-Way Anova, $p<0,05$ ), porém quando comparadas ambas concentrações não foram observadas diferenças significativas (One-Way Anova, $p<0,45$ ).

Segundo Nezzi (2015) quando comparado o peso dos testículos de peixes D.rerio, foi observado um aumento significativo no peso dos testículos de machos expostos à concentração de $65 \mu \mathrm{g} / \mathrm{L}$ de glifosato em comparação com o grupo controle, resultado também constatado por Armiliato et al. (2014) que observaram um aumento significativo no peso das gônadas em fêmeas de peixes D.rerio expostas a mesma concentração de glifosato.

Em estudo realizado por Silva, Barp e Armiliato (2017) as fêmeas de peixes $D$. rerio, expostas a concentração de $65 \mu \mathrm{g} / \mathrm{L}$ de glifosato apresentaram massa corporal significativamente maior do que a das fêmeas mantidas em condições controle.

Os estudos apresentados confirmam os resultados da presente pesquisa, que o glifosato induziu aumentos significativos das massas das gônadas, causando elevação no peso, podendo estar associado à maturação precoce das gônadas, tendo em vista que as células germinativas estão dando resposta em relação as concentrações de glifosato, podendo causar diversos problemas no ciclo reprodutivo dos peixes. 


\section{2 ÍNDICE GONADOSSOMÁTICO}

As médias obtidas para o teste do IGS foram as seguintes, 3,11 (desvio padrão de $\pm 1,3$ ) para o controle, 3,15 (desvio padrão de $\pm 2,2$ ) para a concentração de $65 \mu \mathrm{g} / \mathrm{L}$ e 4,84 desvio (padrão de \pm 1 ) para a concentração de $120 \mu \mathrm{g} / \mathrm{L}$ (Gráfico 2).

Gráfico 2 - Índice Gonadossomático das fêmeas de $D$. rerio expostas aos tratamentos ( \pm Desvio Padrão). Letras diferentes entre os tratamentos indicam diferenças estatísticas (One-Way Anova, $p<0,05)$.

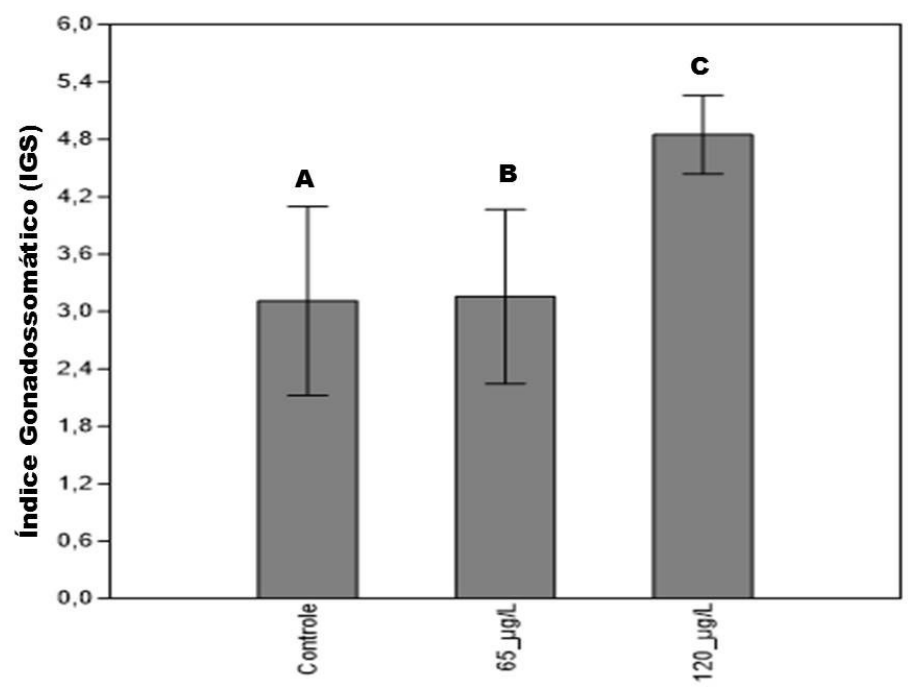

Fonte: Pesquisa (2018).

Os dados referentes ao IGS demonstraram que houve diferença significativa entre as concentrações de glifosato, bem como em relação ao grupo controle. Sendo que o IGS da concentração de $120 \mu \mathrm{g} / \mathrm{L}$ apresentou maior diferença em relação ao IGS da concentração de $65 \mu \mathrm{g} / \mathrm{L},(p<0,03)$.

Segundo Armiliato et al. (2014) a média do IGS das fêmeas de $D$. rerio expostas a $65 \mu \mathrm{g} / \mathrm{L}$ de glifosato apresentou aumentos quando comparadas com as fêmeas não expostas ao herbicida.

Estes dados também se confirmam na pesquisa realizada por Silva, Barp e Armiliato (2017) quando avaliado a média do IGS de fêmeas adultas de $D$. rerio expostas à concentração de $65 \mu \mathrm{g} / \mathrm{L}$ de glifosato em comparação com as fêmeas não expostas ao herbicida (controle). Os resultados indicam que a média do IGS das fêmeas expostas foi significativamente maior. O aumento do IGS é resultante do aumento da expressão de proteínas envolvidas na biossíntese de hormônios esteróides e do sistema endócrino reprodutivo (hipotálamo-hipófise-gonadal) (ARMILIATO et al., 2014).

Conforme relatado neste estudo, verificou-se que o glifosato induziu em aumentos significativos no IGS, devido possíveis alterações ocorridas na secreção 
de hormônios esteroides pelos órgãos reprodutivos, o que induziu a maturação precoce das gônadas e consequentemente a elevação no IGS.

\subsection{MICRONÚCLEOS}

Em relação à incidência de micronúcleos nos eritrócitos dos peixes expostos, obteve-se a média de 9,25 (desvio padrão de \pm 0,4) no grupo controle, 17,16 (desvio padrão de $\pm 0,7$ ) na concentração de $65 \mu \mathrm{g} / \mathrm{L}$ e 30,91 (desvio padrão de $\pm 0,7$ ) na concentração de 120 g/L (Gráfico 3).

Gráfico 3 - Incidência de micronúcleos nos eritrócitos de peixes D.rerio expostos aos tratamentos $( \pm$ Desvio Padrão). Letras diferentes entre os tratamentos indicam diferenças estatísticas (One-Way Anova, <0,05).

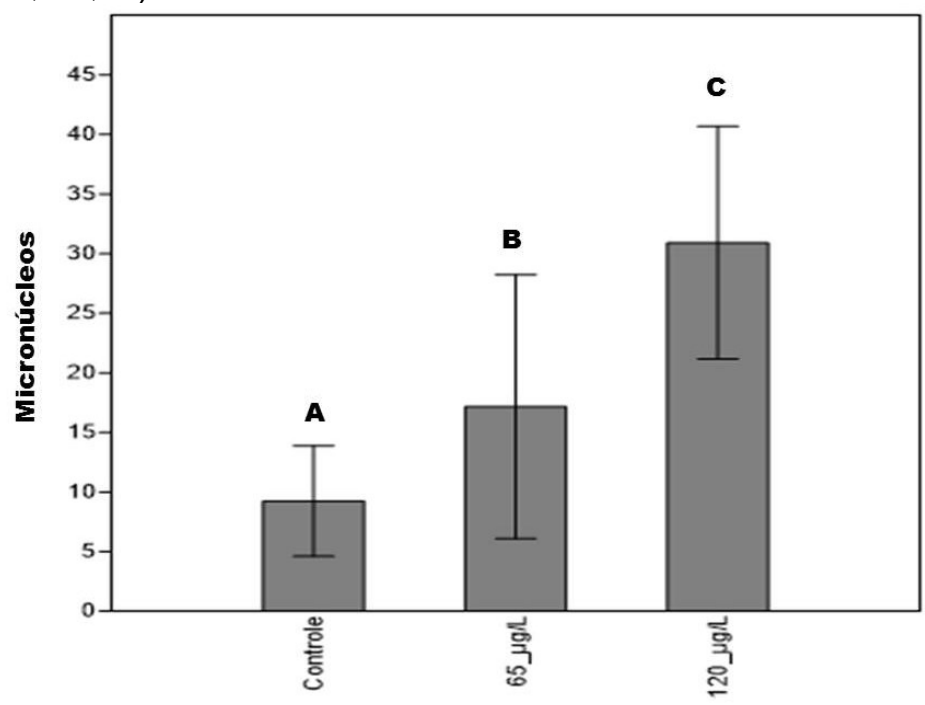

Fonte: Pesquisa (2018).

Os dados apresentados demonstram que a maior concentração de glifosato, levou a um aumento na formação de micronúcleos. Sendo observado que a ocorrência de micronúcleos foi significativamente maior na concentração de 120 $\mu \mathrm{g} / \mathrm{L}$ em comparação com a concentração de $65 \mu \mathrm{g} / \mathrm{L}$ (One-Way Anova, $p<0,05$ ), sendo possível visualizar em alguns casos a formação de dois micronúcleos por eritrócitos (Figura 2). 
Figura 2 - Eritrócitos normais sem presença de micronúcleos (a), eritrócitos com presença de micronúcleo da concentração de $65 \mu \mathrm{g} / \mathrm{L}$ (b) e eritrócitos com presença de até dois micronúcleos por eritrócitos da concentração de $120 \mu \mathrm{g} / \mathrm{L}$ (c).

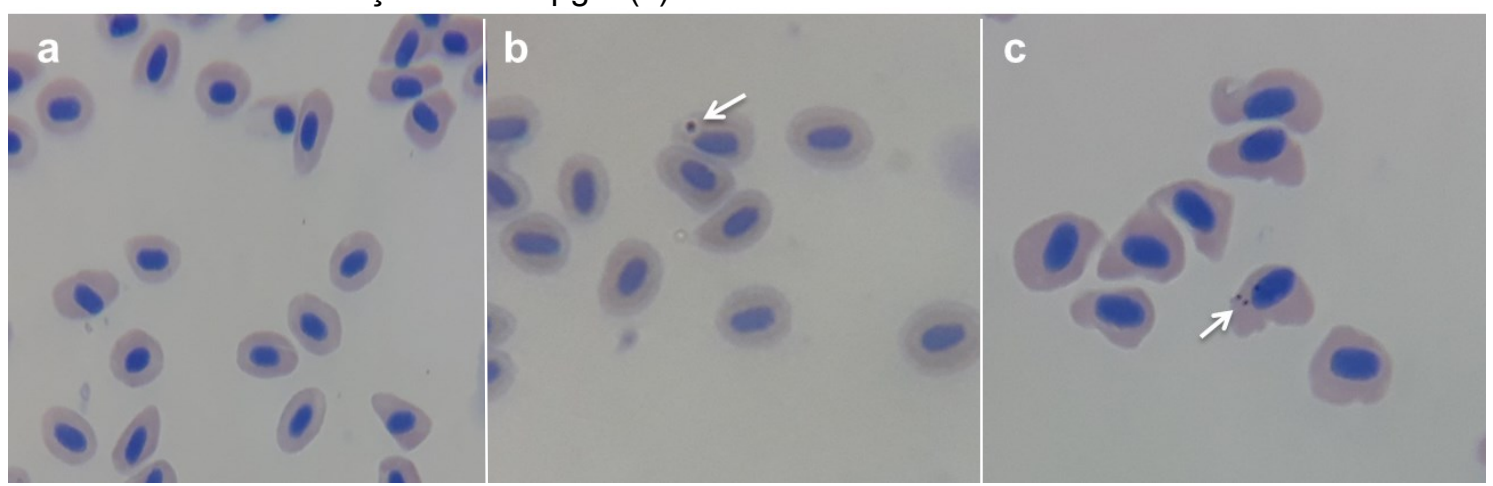

Fonte: Dados da pesquisa (2018).

Quando comparada a frequência de micronúcleos dos grupos expostos a 120 $\mu \mathrm{g} / \mathrm{L}$ e $65 \mu \mathrm{g} / \mathrm{L}$ do herbicida, ambas foram estatisticamente significativas em relação ao grupo controle.

Com base nesses resultados, observou-se que o glifosato induziu a formação de micronúcleos mesmo na concentração permitida pelo CONAMA (65 $\mu \mathrm{g} / \mathrm{L})$. Resultados estes também observados por Nezzi (2015) ao qual, demonstrou que o glifosato na concentração máxima permitida pelo CONAMA de $65 \mu \mathrm{g} / \mathrm{L}$, induziu num aumento significativo na frequência de micronúcleos em células sanguíneas das brânquias de machos de D.rerio após $360 \mathrm{~h}$ de exposição.

Contudo, os resultados do presente estudo demonstraram que os peixes que permaneceram em exposição a maior concentração de herbicida (120 $\mu \mathrm{g} / \mathrm{L})$ apresentaram aumentos significativos na frequência de eritrócitos micronucleados, demonstrando que o potencial genotóxico do glifosato pode aumentar em diferentes concentrações.

Estudos realizados por Ghisi, Oliveira e Prioli (2016) comparando diversas concentrações de glifosato em peixes, camundongos e crocodilos, demonstraram que quanto mais altas forem as concentrações de glifosato maiores serão os aumentos na formação de micronúcleos, mas com o decorrer do tempo de exposição, a formação de micronúcleos diminuiu. Isso pode ser explicado pela adaptação de mecanismos de desintoxicação e metabolização de xenobióticos e reparo de danos no DNA ao longo do tempo de exposição.

Para Cavas e Konen (2007) as frequências de micronúcleos nos eritrócitos aumentaram significativamente após o tratamento com o glifosato em concentrações 5, 10 e 15 ppm em peixes Carassiusauratus (peixe dourado).

Constatou-se que o herbicida glifosato pode acarretar em danos clastogênicos e aneugênicos em eritrócitos de peixes, bem como, o potencial genotóxico pode ser ampliado conforme o aumento da concentração deste xenobiótico e acarretar em danos celulares. 


\section{CONCLUSÃO}

O glifosato, em ambos os tratamentos, causou aumentos estatisticamente significativos na massa gonadal, mas não apresentaram diferenças distintas entre as diferentes concentrações testadas do herbicida.

Foram verificados aumentos significativos entre o IGS quando comparadas as concentrações do glifosato em relação ao grupo controle, quando comparadas ambas as concentrações de glifosato a maior concentração testada do herbicida apresentaram maior significância.

Em conclusão, o presente estudo constatou que o herbicida glifosato pode causar danos à biologia reprodutiva, bem como, ocasionar distúrbios celulares nos peixes da espécie $D$. rerio. Os efeitos adversos do glifosato sobre os ovários demonstrados aqui, alertam para os efeitos nocivos que este xenobiótico pode causar na reprodução de peixes, o que possivelmente pode interferir no ciclo reprodutivo destes organismos.

\section{REFERÊNCIAS}

AL-SABTI, K. Clastogenic effects of live carcinogenic-mutagenic chemicals on the cells of the common carp (Cyprinus carpio L.). Comparative Biochemistry and Physiology, v. 85C, p.5-9, 1986.

ANDRADE, Rui Miguel Sanches Linhares de. Efeitos da exposição de peixe zebra, Danio rerio, a um efluente têxtil. 2004. 100 f. Dissertação (Mestrado) - Curso de Ecologia Aplicada, Departamento de Zoologia e Antropologia, Faculdade de Ciências da Universidade do Porto, Porto, 2004.

ARMILIATO, Neide; MÜLLER, Yara Maria Rauh; AMMAR, Dib. Toxicidade celular e bioquímica do glifosato sobre os ovários do peixe Danio rerio. 2014. 109 f. Tese (Doutorado) - Curso de Biologia Celular, Universidade Federal de Santa Catarina, Florianópolis-SC, 2014.

BEGUM, G. Carbofuran insecticide induced biochemical alterations in liver and muscle tissues of the fish Clarias batrachus (Linn) and recovery response. Aquatic Toxicology, 66: 83-92, 2004.

BITTENCOURT, F. et al. Benzocaína e eugenol como anestésicos para o quinguio (Carassius auratus). Arquivo Brasileiro de Medicina Veterinária e Zootecnia, v. 64, n. 6, p.1597-1602, dez. 2012. 
CAJARAVILLE, M.P. et al. The use of biomarkers to assess the impact of pollution in coastal environments of the Iberian Peninsula: a practical approach. The Science of the Total Environment, v. 247, n. 2-3, p. 295-311, 2000.

CAVAS, T.; KONEN, S. Detection of cytogenetic and DNA damage in peripheral erythrocytes of goldfish (Carassius auratus) exposed to a glyphosate formulation using the micronucleus test and the comet assay. Mutagenesis, v. 22, n. 4, p. 263268, 10 abr. 2007. Oxford University Press (OUP).

http://dx.doi.org/10.1093/mutage/gem012.

CESTARI, M. M. et al. Mutagenic effects of tributyltin (TBT) and inorganic lead (PbII) on the fish $H$. malabaricusas evaluated using the comet assay, piscine micronucleous and chromosome aberrations tests. Genetics and Molecular Biology, v. 27, n. 1, p. 103-107, 2004.

FONSECA, M. B. 2007. Crescimento e parâmetros toxicológicos em jundiás (Rhamdiaquelen) expostos a uma formulação comercial do herbicida 2,4Diamin. 67 p., 2007. Dissertação (Mestrado) - Universidade de Santa Maria/RS, 2007.

GHISI, Nédia de Castilhos; OLIVEIRA, Elton Celton de; PRIOLI, Alberto José. Does exposure to glyphosate lead to an increase in the micronuclei frequency? A systematic and meta-analytic review. Chemosphere, v. 145, p.42-54, fev. 2016. Elsevier BV. Disponível em: http://dx.doi.org/10.1016/j.chemosphere.2015.11.044.

GOLDFARB, P.; LIVINGSTONE, D.; BIRMELIN, C. Biomonitoring in the aquatic environment: use of molecular biomarkers. Biochemical Society Transactions, v. 26, n. 4, p. 690-694, 1998.

GRISOLIA, C. K. Agrotóxicos: mutações, câncer \& reprodução. Brasília: editora Universidade de Brasília, 2005.

METCALFE, C. D. Testes for Predicting Carcinogenecity in Fish. CRC Critical Reviews in Aquatic Sciences, v. 1, p.111-129, 1989.

MONSERRAT, J.M.; GERACITANO, L.A.; BIANCHINI, A. Current and future perspectives using biomarkers to assess pollution in aquatic ecosystems.

Comments on Toxicology, v. 9, p. 255-269, 2003.

NEZZI, Luciane. Efeito do herbicida glifosato sobre as células somáticas e germinativas de testículo de peixe Danio rerio. 2015. 79 f. Dissertação (Mestrado em Biologia Celular) - Centro de Ciências Biológicas, Universidade Federal de Santa Catarina, Florianópolis-SC, 2015.

NIGRO, M. et al. Cellular biomarkers for monitoring estuarine environments: transplanted versus native mussels. Aquatic Toxicology, v. 77, n. 4, p. 339-347, 2006. 
PIGNATI, Wanderlei Antonioet al. Distribuição espacial do uso de agrotóxicos no Brasil: uma ferramenta para a Vigilância em Saúde. Ciência \& Saúde Coletiva, v. 22, n. 10, p.3281-3293, out. 2017. FapUNIFESP (SciELO). http://dx.doi.org/10.1590/1413-812320172210.17742017.

SANTA CATARINA. SECRETARIA DE ESTADO DO DESENVOLVIMENTO URBANO E MEIO AMBIENTE. Bacia hidrográfica do Estado de Santa Catarina: diagnóstico geral. Governo de Santa Catarina: Florianópolis, 1997.

SCHUMACHER, Mauro Valdir; HOPPE, Juarez Martins. A floresta e a água. Porto Alegre: Pallotti, 1998.

SILVA, Tainan Filipe da; BARP, Elisete Ana; ARMILIATO, Neide. Avaliação da toxicidade celular do glifosato sobre as gônadas de Danio rerio. (Cyprinidae). Saúde e Meio Ambiente, v. 1, n. 6, p.85-95, jun. 2017.

Artigo recebido em: 24/07/2018

Artigo aprovado em: 21/01/2019

Artigo publicado em: 01/02/2019 